\title{
The winner takes it all: Outperformance drives subsequent flows in South African Unit Trust Funds
}

\author{
Jennifer Arendse, Chris Muller and Michael Ward \\ Gordon Institute of Business Science, University of Pretoria, South Africa \\ CONTACT Chris Muller (chrism@iafrica.com); Michael Ward (mchlwrd@gmail.com)
}

\begin{abstract}
The relationship between unit trust (mutual fund) performance and subsequent investment flows into and out of funds has been the focus of many international studies. Emerging markets, which are characterised by higher risk, weaker institutions, volatile economies and fewer participants, provide an attractive opportunity to examine the flow-performance problem in the context of higher arbitrage costs.
\end{abstract}

This study builds on the findings in the literature of the flow-performance relationship and aims to examine in more detail, and to quantify, the inflow into funds which outperform. The flowperformance relationship is important for investment businesses to understand because of the significant implications this has on the profitability of funds.

The research applies a portfolio time-series methodology to Morningstar's South African fund data, using a buy-and-hold analysis. Two unit trust categories are tested, namely General Equity and Multi-asset High Equity funds, and within each category, single manager funds and fund of funds are tested separately.

Funds are ranked by their past performance over an optimised 14-month look-back period, and assigned into quintiles. Net flows into each fund in the subsequent quarter are then determined, and the process rolled over on a quarterly basis from 2000 to 2015 . We find convincing evidence from an emerging market perspective that equity funds need to perform in the top quintile to attract funds, and observe that relative performance to peers is more important to investors than performance relative to other benchmarks. One additional inference is that the South African unit trust industry is set to face consolidation.

\section{Keywords}

Flow-performance relationship, prediction of fund flows, unit trust funds 


\section{Introduction}

The single most important issue in the investment management industry is to increase funds under management. This is because profitability is dependent upon fee income, which is directly linked to the size of the asset base, whilst costs are (relatively) more or less fixed. There are, of course, many reasons presented in academic literature as to why investors select particular funds, but past performance has been shown to be the dominant factor. Unsurprisingly, a consensus exists that there is a positive association between fund performance and subsequent inflows; those funds exhibiting the best historical performance attract new investors, at the expense of funds which underperform.

The aim of this study is to explore the extent to which this relationship, which is evident in the international literature, holds true in an emerging market context. Furthermore, the study seeks to measure several key metrics; in particular the level of out-performance necessary to attract new capital, as well as the optimal look-back period over which investors determine out-performance.

\section{Theory and Literature Review}

There are several inter-related theories predicting a positive correlation between fund performance and subsequent flows into or out of funds. The most obvious of these have suggested that investors view good performance as an indicator of quality (Ippolito, 1992) and managerial ability (Huang, Wei, \& Yan, 2007) and therefore they reward good performance with new investments. In addition, Sirri and Tufano (1998) suggest that investors choose high performing funds simply to reduce search and participation costs.

In contrast to these theories, Singal and Xu, (2011) define a "disposition effect" as the tendency to sell good performing funds to realise capital gains and to hold on to poor performing funds to recover losses; although this has been shown to be more applicable to individual shares than to unit trusts (Bailey, Kumar, \& Ng, 2011).

Rudman (2008) defines a trend-chasing behaviour (also known as feedback-trading) as the tendency to chase fund performance. Berk and Green (2002) suggest that this is consistent with corporate finance valuation models, in that funds flow to productive investments, but they argue that investors cannot expect predictability of future performance when making decisions based on this premise. Indeed, Bailey et al. (2011) show that funds which experienced significant inflows can find it difficult to maintain out-performance because of increased trading costs and mandate constraints. Pillay, Muller and Ward (2010), in their study on the Johannesburg stock exchange (JSE), found that performance was affected for fund sizes greater than about R5bn, since larger funds are increasingly forced towards market-cap weightings, making it difficult to out-perform the benchmark. 
Karpoff (1987) found that the flow-performance link was asymmetrical, i.e. it was fundamentally different for positive and negative returns and differed depending on the type of investor, how big the market was and the market cycle under which the investment decision was made. Sirri and Tufano (1998) ascribe this to rational behaviour, relating to search and switch costs, while others explain it in the context of behavioural economics, citing status-quo bias and cognitive dissonance as reasons (Goetzmann \& Peles, 1997).

Sawicki (2001), in a study of the Australian market, reported a different response for retail versus institutional investors towards negative and positive returns. For retail investors, the flowperformance relationship was "convex", whereas institutional investors "punished" poor performance by withdrawing funds.

Ferreira, Keswani, Miguel and Ramos (2012) tested the flow-performance link in 28 countries. They found that mutual fund investors in developed countries were more proactive in selling poor performing funds and displayed less trend-chasing behaviour. This was partly due to higher education levels and improved institutions and systems in developed countries, which enabled better processing of information and led to more sophisticated investors.

Edelen and Warner (2001) showed that market conditions affected fund flows. They showed behavioural factors to be more influential during periods of market declines. In bull markets, investors held on to poor performers and did not punish them - an asymmetrical relationship. In bear markets, investors did not discriminate and punished or rewarded good and poor performers equally - a symmetrical relationship.

Ivković and Weisbenner (2009) found a relationship between fund inflows and the relative performance of a fund, and between fund outflows and the absolute performance of the fund. They tested the determinants of mutual fund flows from an individual investor perspective and found that, generally, inflows are driven by the funds' relative performance measures, defined as the funds' performance relative to other funds with the same objective over the past year. This implies that decisions to invest were guided by who the best performers are in a sector, without any consideration for the funds' absolute return, i.e. actual return. In contrast, outflows were driven by the absolute returns of the fund over one year.

Studies have attempted to determine the variation of fund flows by considering how the flows differ between top quartile and bottom quartile performers. Ivković and Weisbenner (2009) found that fund inflows were seen to be $3.3 \%$ higher for funds with top quintile performance, compared to funds that performed in bottom quintiles. Ben-Rephael, Kandel, and Wohl (2012) reported an excess market return of $1.95 \%$ was also found to be consistent with additional flow. Similarly, Blanchett (2012) noted that although top performers did not attract all the fund flows, they certainly attracted the bulk, with the top-quartile performers attracting three times the inflows of bottom quartile performers.

In summary, theory supports a positive relationship between performance and subsequent fund 
flows because good performance is an indicator of skill (Ippolito, 1992), of managerial ability (Huang, Wei, \& Yan, 2007), and can reduce costs Sirri and Tufano (1998). A 1987 meta-analysis to consolidate the findings of various studies that tested this relationship over the period of 19641987 found that 18 out of 19 studies confirmed the positive correlation (Karpoff, 1987). However, several more nuanced studies have noted that this general relationship may be different for large funds (Pillay, Muller \& Ward 2010), or retail versus institutional investors (Karpoff, 1987 and Sawicki, 2001) or for different phases of the economic cycle (Karpoff, 1987 and Edelen \& Warner, 2001).

South African financial markets are characterised by high risk and volatile conditions because of relatively weaker institutions and a volatile economic environment with fewer participants. The level of arbitrage is related to the level of liquidity, turnover and trading costs (Li \& Zhang, 2010; Shleifer \& Vishny, 1997).

Although South African financial markets rank amongst the largest and most liquid of emerging markets, the availability of detailed fund data is limited by the Association of Savings and Investment South Africa (ASISA), and only one relevant study exists. Rudman (2008), using available South African data for General Equity funds, investigated the determinants of fund flows using the following independent variables: interest rates, returns, costs, past flows, fund category flows, risk, fund age, fund size and performance measures. The study found that fund returns had the strongest correlation with inflows (Rudman, 2008).

This study uses a longer time-series and a bigger sample of funds. Furthermore, an improved methodology permits the measurement of both the degree of out-performance necessary to attract flows (and vice-versa) as well as the optimisation of the look-back period over which investors measure performance.

\section{Research questions}

Following the literature, we examine the association between fund performance and subsequent net flows into or out of funds in an emerging market:

We state the null and alternative hypothesis as follows:

$\mathrm{H}_{0}$ : There is no association between fund performance and subsequent investment flows into or out of funds.

$\mathrm{H}_{\mathrm{a}}$ : There is a positive association between fund performance and subsequent investment flows into or out of funds.

Arbitrage costs (including brokerage, tax and market impact costs) are significantly higher in South Africa than in other developed economies. This context therefore provides an attractive opportunity to examine the question: does the fund-performance relationship change with high risk and high arbitrage costs? We seek to identify the degree of out-performance necessary to attract flows, as well as the optimal look-back period over which investors measure performance. 


\section{Research Methodology}

The universe for this study was all unit trust funds in South Africa, listed since 31 January 2000 upto 31 December 2015. The study does not suffer from survivorship bias and contains no missing data (as far as possible). Stratified random sampling was applied, from a full sample frame obtained from Morningstar SA (Saunders \& Lewis, 2012).

As at 30 June 2015, the collective investment schemes (CIS) industry in SA had approximately R1 781bn assets under management, with a total number of 1225 funds (Association of Savings and Investments, 2015). The sectors selected were those identified with the highest fund flows and number of funds. (Money market funds were excluded from the study because flows to these unit trust funds are generally driven by fluctuations in interest rates.) Single manager funds, the ten largest funds and fund of funds (FOFs) in the two major sectors below, were tested:

South African - General Equity: (R316bn in 196 funds).

South African - Multi-asset - High Equity: (R368bn in 165 funds).

Although the sample represents less than $30 \%$ of the number or funds, it does represent approximately $95 \%$ of the value in South African equity funds.

Several methodologies for testing the association between past performance and fund flows can be seen in the literature. Alves and Mendes (2011) used contingency tables. Whilst this is a simple and robust approach, others have complemented the analysis using multi-variate regression (Cashman, Deli, Nardari, \& Villupuram, 2007). Given the limitations of these methodologies, significant improvements can be made in the robustness of the findings by applying a portfolio timeseries methodology, in the form of a buy-and-hold style analysis (Muller \& Ward, 2013). This methodology has the combined advantage of reducing volatility in time-series returns (by constructing portfolios), and by cumulating the returns over several years the effects are much stronger.

The methodology is summarised as follows:

1. On 31 Dec 2001 the funds (in existence as defined by the relevant sample) were determined.

2. Each fund was ranked by past performance (as reported by Morningstar) over a "look-back period", initially set at 1 month. (The look-back period, measured in months, could be varied between 1 and 24 months - see step 7).

3. Each fund was then allocated, on an equal-weighted basis, into the appropriate quintile.

4. The subsequent net flows into each quintile were computed for the following quarter, and the daily quintile performance over the quarter was calculated, indexed starting from 1.0. The value of each quintile was retained at the end of the quarter.

5. On 31 Mar 2002 the quintiles were re-balanced. New funds were included into the sample as their data became available from Morningstar. Steps 2 to 4 above were repeated, but 
with the cumulative value of each quintile being retained.

6. The process was repeated, with quarterly re-balancing of quintiles, until 30 Mar 2015.

7. Finally, the look-back period (over which performance was measured) was optimised by rerunning the entire process for lookback periods from 1 month to 24 months. The highest performance spread between quintiles one and five over the entire 15 year period was found to occur with a lookback period of 14 months.

8. The annualised cumulative growth in fund size for each quintile was measured as a multiplier (equation 1), and the time series results graphed. The annualised return on each quintile was calculated as shown in equation 2.

Equation 1:

$$
\text { FundSizeMultiplier }=\frac{\text { SizeOfQuintile }_{i} \text { at } 31 \text { st Dec } 2015}{\text { SizeOfQuintile }_{i} \text { at } 31 \text { st Dec } 2000}
$$

Equation 2:

$$
\text { AnnualisedQuintileReturn }=\left(\frac{\text { ValueOfQuintil }_{i} \text { at } 31 \text { st Dec 2015 }}{\text { ValueofQuintile }_{i} \text { at } 31 \text { st Jan 2000 }}\right)^{\frac{1}{15}}-1
$$

To test whether the differences in the cumulative flows between Quintile1 and Quintile 5 were significantly different, Friedman's non-parametric Anova test was used, since the assumption of normality was not met for all categories (Field, 2013). For each category, the test statistic, degrees of freedom and significance level applied at a $5 \%$ level are reported.

To examine the relationship between subsequent flows into funds versus prior returns a scatterplot and simple regression analysis was conducted. The flow into each quintile was the annualised fund flow into each quintile over the 15 year period and the return was measured as the excess return (over/under the average) for each quintile. The categories of funds were combined for this analysis.

A fund may have multiple share classes, each listed separately. All share classes are managed in the same way, the only difference being differing levels of fees between retail and institutional investors. For the purposes of this study, the share class with the worst performance was used, typically the retail share class. 


\section{Results}

Two figures and one table are shown below for each category of fund investigated. In the first figure, the lines represent the cumulative build-up of flows, indexed from 1. The number at the end of each line represents the multiplication factor (equation 1) by which the fund size increased over the time-series (i.e. a multiplication factor of $10.9 x$ (Figure 1) for Quintile 1 would mean that the fund flows into Quintile 1 over the 15 year study period amounted to 10.9 times the starting value in Jan 2000). The second graph shows the performance of each quintile, measured as the cumulative value of the quintile, indexed from 1. The numbers at the end of the lines are the annualised returns (equation 2), for each quintile. The green line represents the price relative (i.e. the cumulative value of the best fund divided by the value of the worst fund (Quintile 1/Quintile 5)).

The tables below show the annualised percentage by which the fund's size increased every year and the annualised return of each quintile. We also show the annualised cumulative multiple of fund flow into Quintile 1 versus Quintile 5, and present the results of the Friedman ANOVA test, as described above.

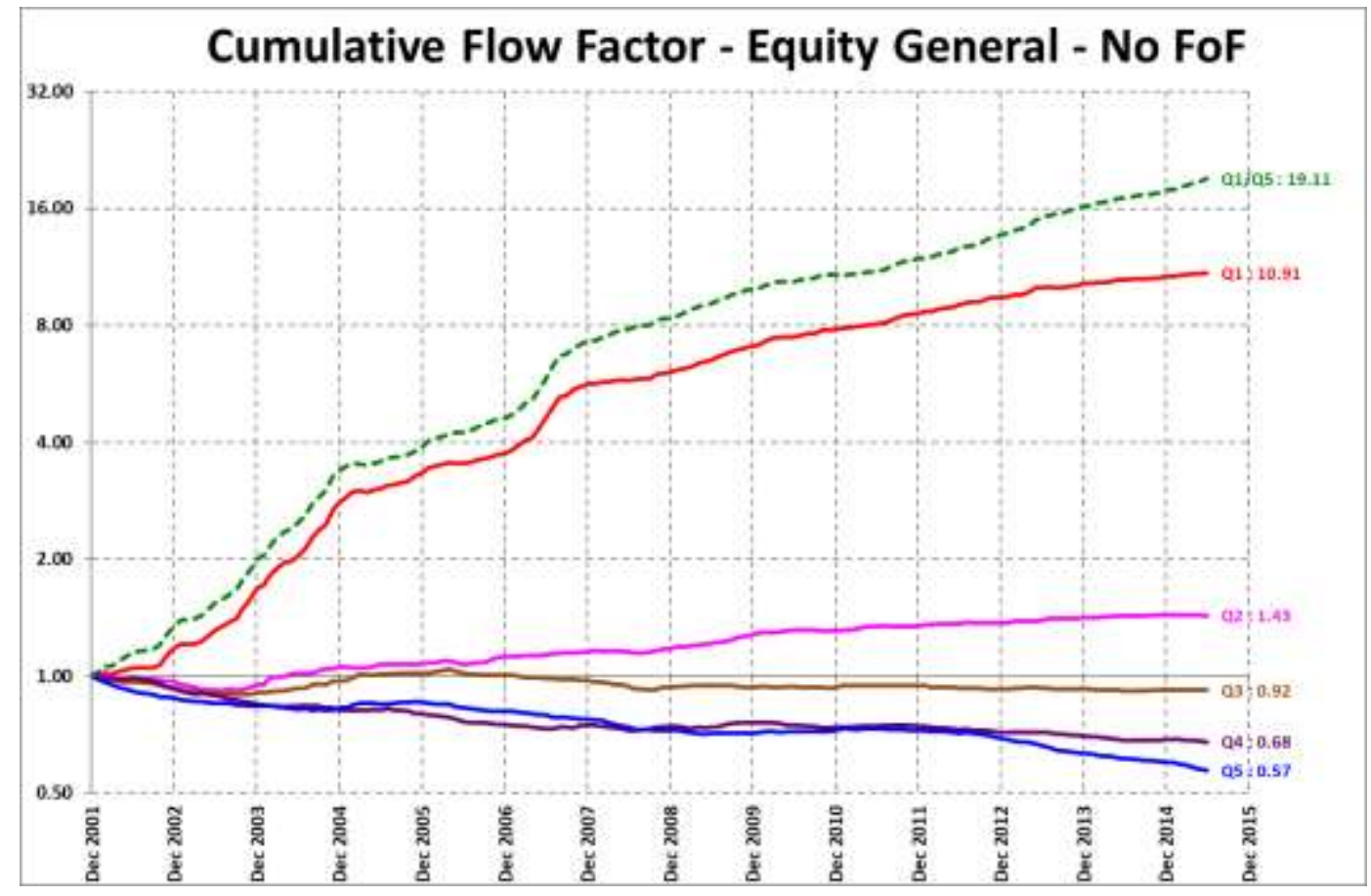

Figure 1: Cumulative annualised flows for quintiles - General Equity (excluding FOFs) 


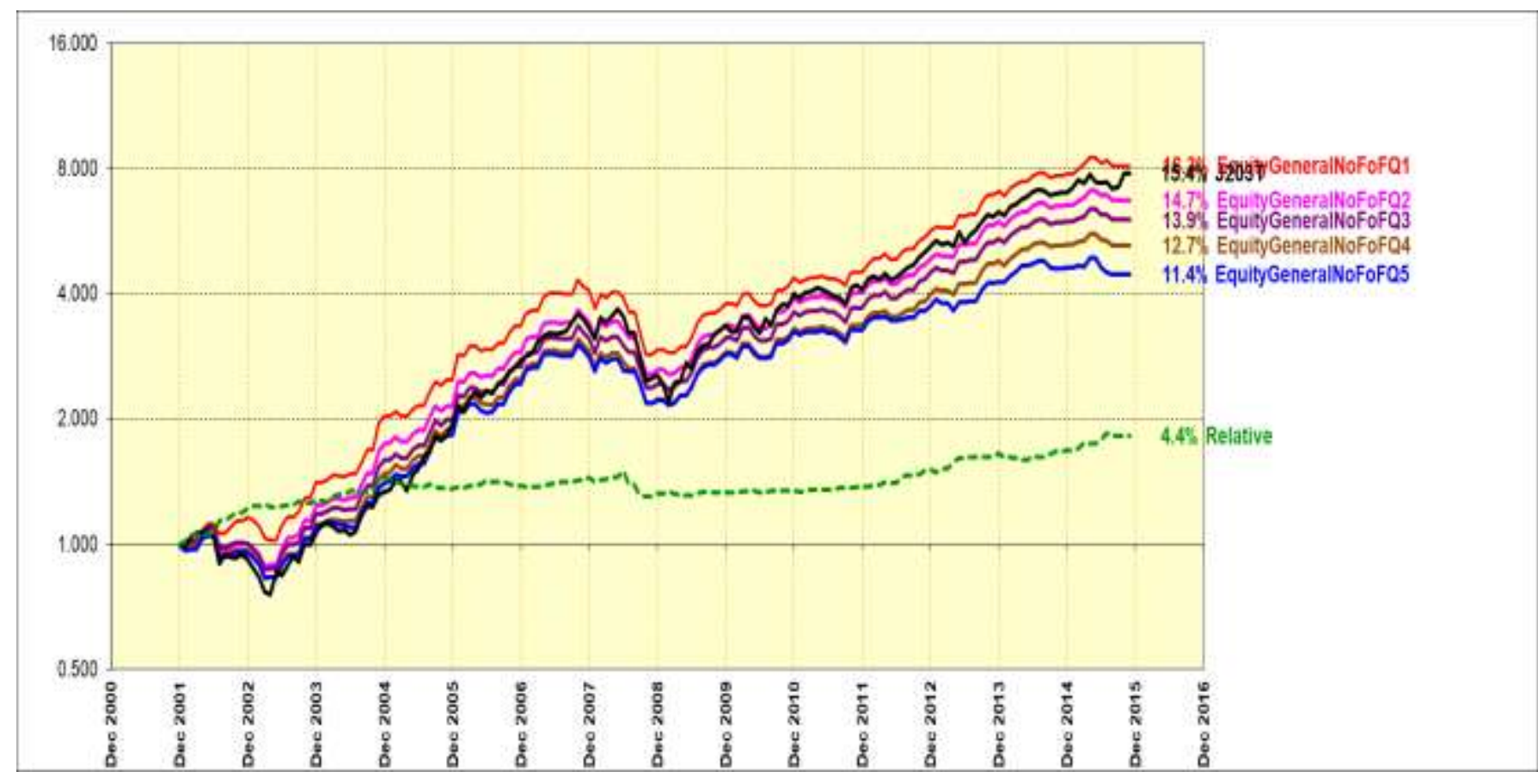

Figure 2: Cumulative annualised returns for quintiles - General Equity (excluding FOFs)

Table 1: Cumulative annualised returns and flows for quintiles - General Equity (excluding FOFs)

\begin{tabular}{|l|c|c|c|c|c|c|c|}
\hline & Q1 & Q2 & Q3 & Q4 & Q5 & (Q1/Q5) & ALSI \\
\hline Annualised returns \% & $16.0 \%$ & $14.5 \%$ & $13.6 \%$ & $12.5 \%$ & $11.2 \%$ & $4.4 \%$ & $14.8 \%$ \\
\hline Annualised flow \% & $19.4 \%$ & $2.7 \%$ & $-0.6 \%$ & $-2.8 \%$ & $-4.1 \%$ & $24.4 \%$ & \\
\hline $\begin{array}{l}\text { Cumulative Fund-flow } \\
\text { factor }\end{array}$ & 10.9 & 1.4 & 0.9 & 0.7 & 0.6 & 19.1 & \\
\hline
\end{tabular}

Friedmans's ANOVA test: $n=162, \quad D O F=4, \quad$ Significance $=5 \%$, Statistic $=330$

Result: Reject null hypothesis 
General Equity (excluding FOFs) - Top 10 only

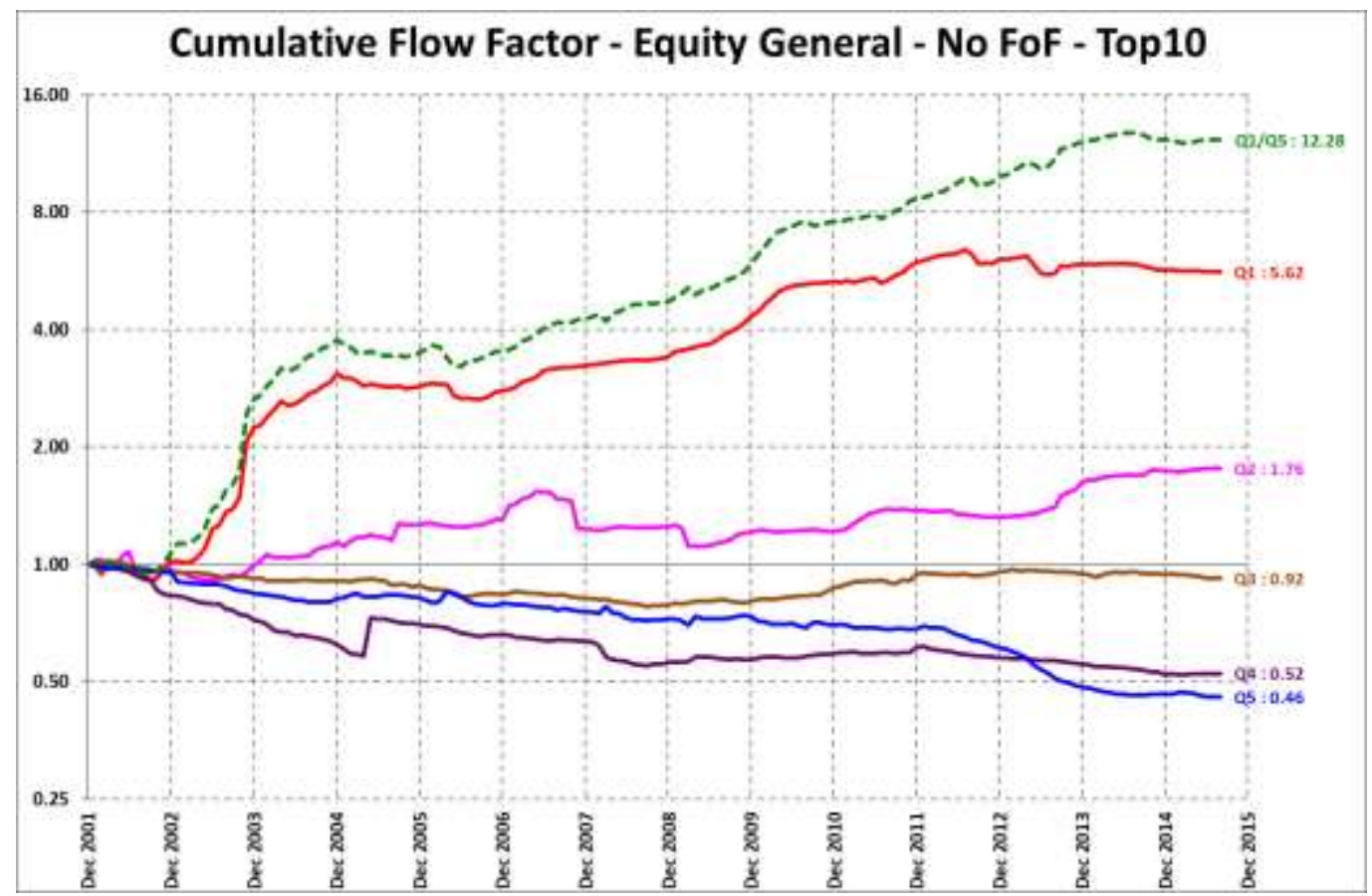

Figure 3: Cumulative annualised flows for quintiles - Top 10 General Equity

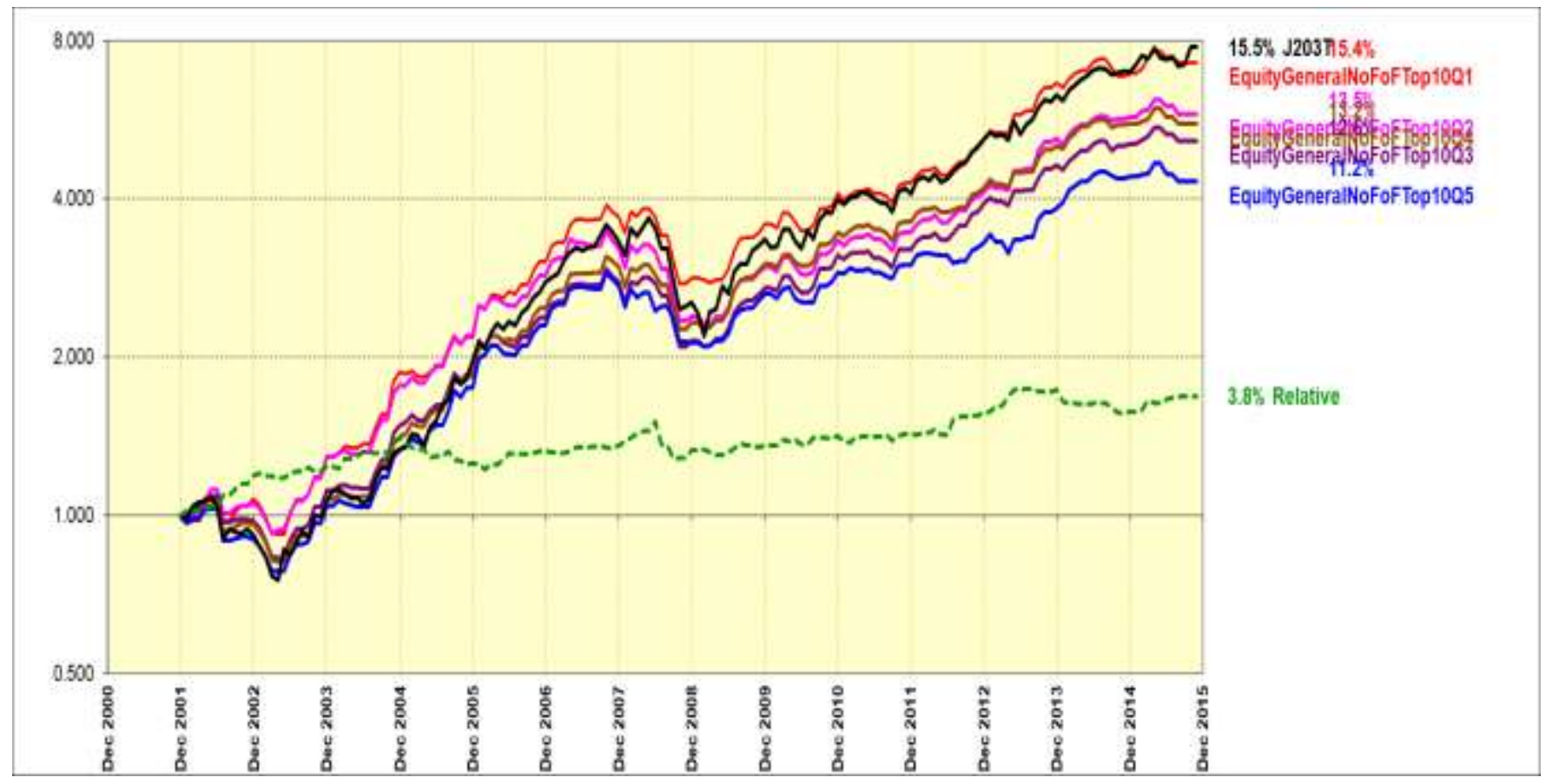

Figure 4: Cumulative annualised returns for quintiles - Top 10 General Equity 
Table 2: Cumulative annualised returns and flows for quintiles - Top 10 General Equity

\begin{tabular}{|l|c|c|c|c|c|c|c|}
\hline & Q1 & Q2 & Q3 & Q4 & Q5 & (Q1/Q5) & ALSI \\
\hline Annualised returns \% & $15.4 \%$ & $13.3 \%$ & $13.0 \%$ & $12.3 \%$ & $10.9 \%$ & $3.8 \%$ & $14.8 \%$ \\
\hline Annualised flow \% & $13.5 \%$ & $4.2 \%$ & $-0.6 \%$ & $-4.6 \%$ & $-5.6 \%$ & $20.1 \%$ & \\
\hline $\begin{array}{l}\text { Cumulative Fund-flow } \\
\text { factor }\end{array}$ & 5.6 & 1.8 & 0.9 & 0.5 & 0.5 & 12.3 & \\
\hline
\end{tabular}

Friedmans's ANOVA test: $\mathrm{n}=164, \mathrm{DOF}=4$, Significance $=5 \%$, Statistic $=105$

Result: Reject null hypothesis

General Equity - FOF only

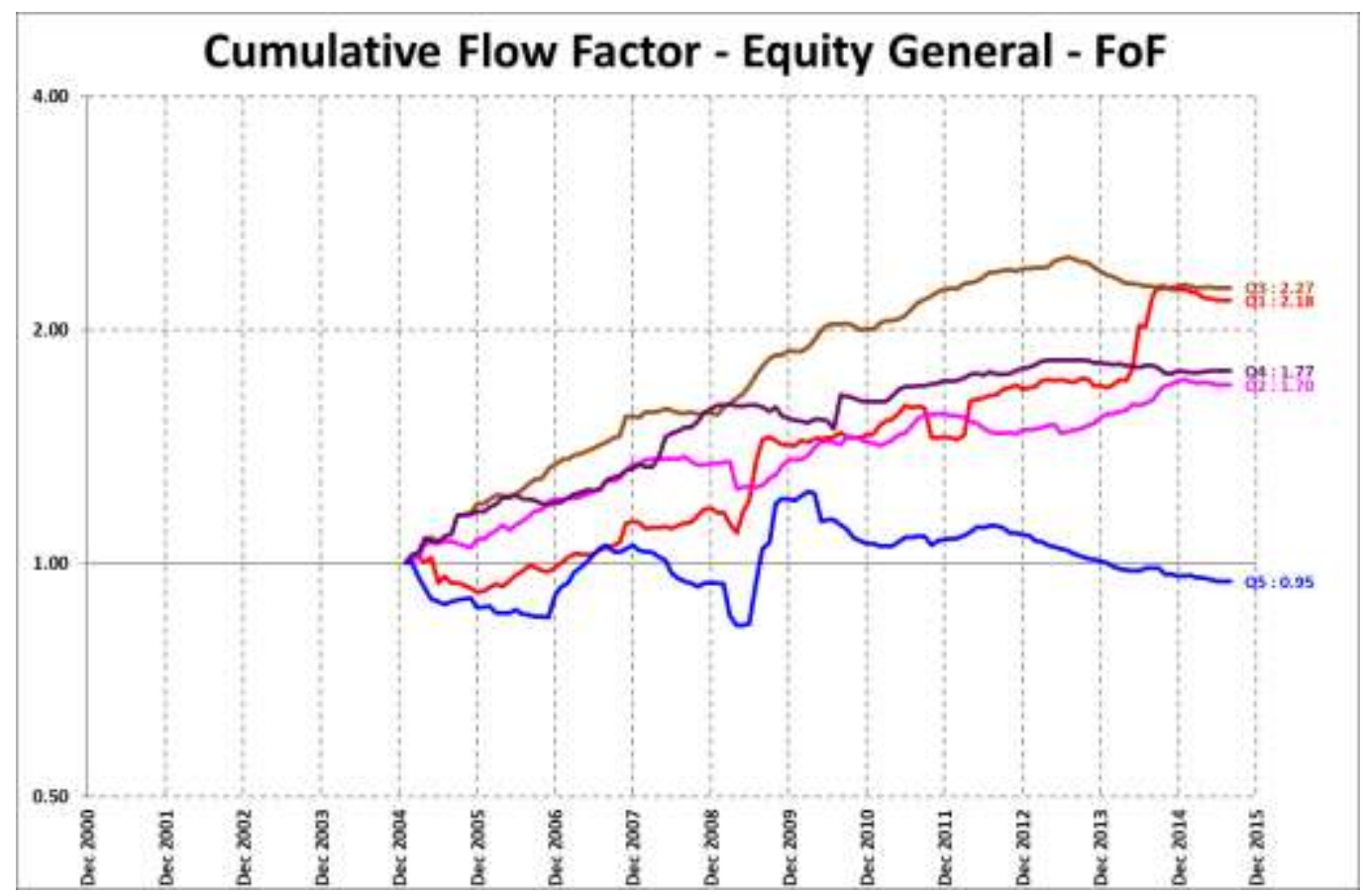

Figure 5: Cumulative annualised flows for quintiles - General Equity -FOFs 


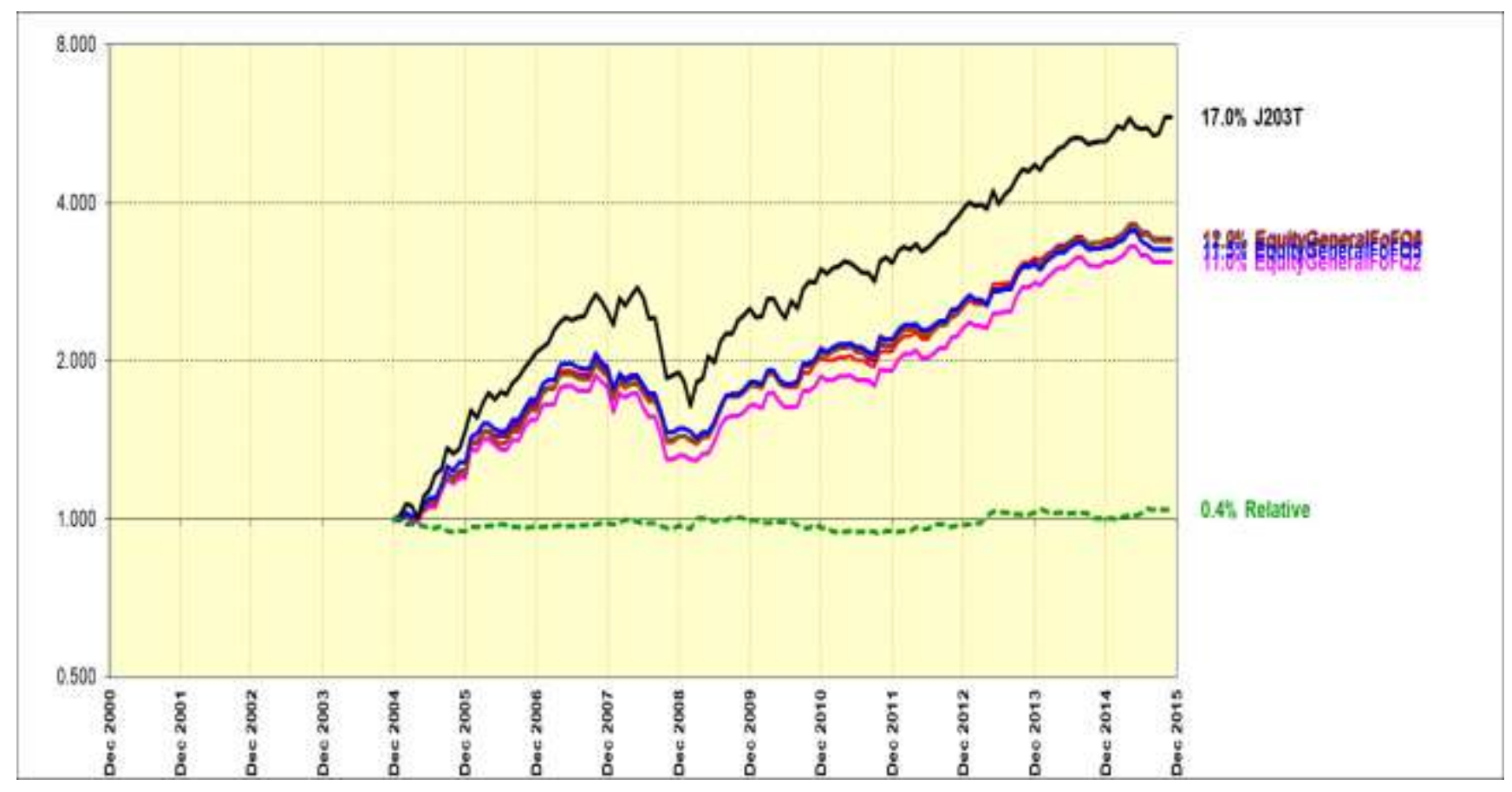

Figure 6: Cumulative annualised returns for quintiles - General Equity -FOFs

Table 3: Cumulative annualised returns and flows for quintiles - General Equity - FOFs

\begin{tabular}{|l|c|c|c|c|c|c|c|}
\hline & Q1 & Q2 & Q3 & Q4 & Q5 & (Q1/Q5) & ALSI \\
\hline Annualised returns \% & $11.6 \%$ & $10.7 \%$ & $11.7 \%$ & $11.6 \%$ & $11.2 \%$ & $0.4 \%$ & $16.1 \%$ \\
\hline Annualised flow \% & $7.6 \%$ & $5.1 \%$ & $8.0 \%$ & $5.5 \%$ & $-0.5 \%$ & $20.1 \%$ & \\
\hline $\begin{array}{l}\text { Cumulative Fund-flow } \\
\text { factor }\end{array}$ & 2.2 & 1.7 & 2.3 & 1.8 & 1.0 & 2.3 & \\
\hline
\end{tabular}

Friedmans's ANOVA test: $n=127, \quad D O F=4$, Significance $=5 \%$, Statistic $=19$

Result: Reject null hypothesis 


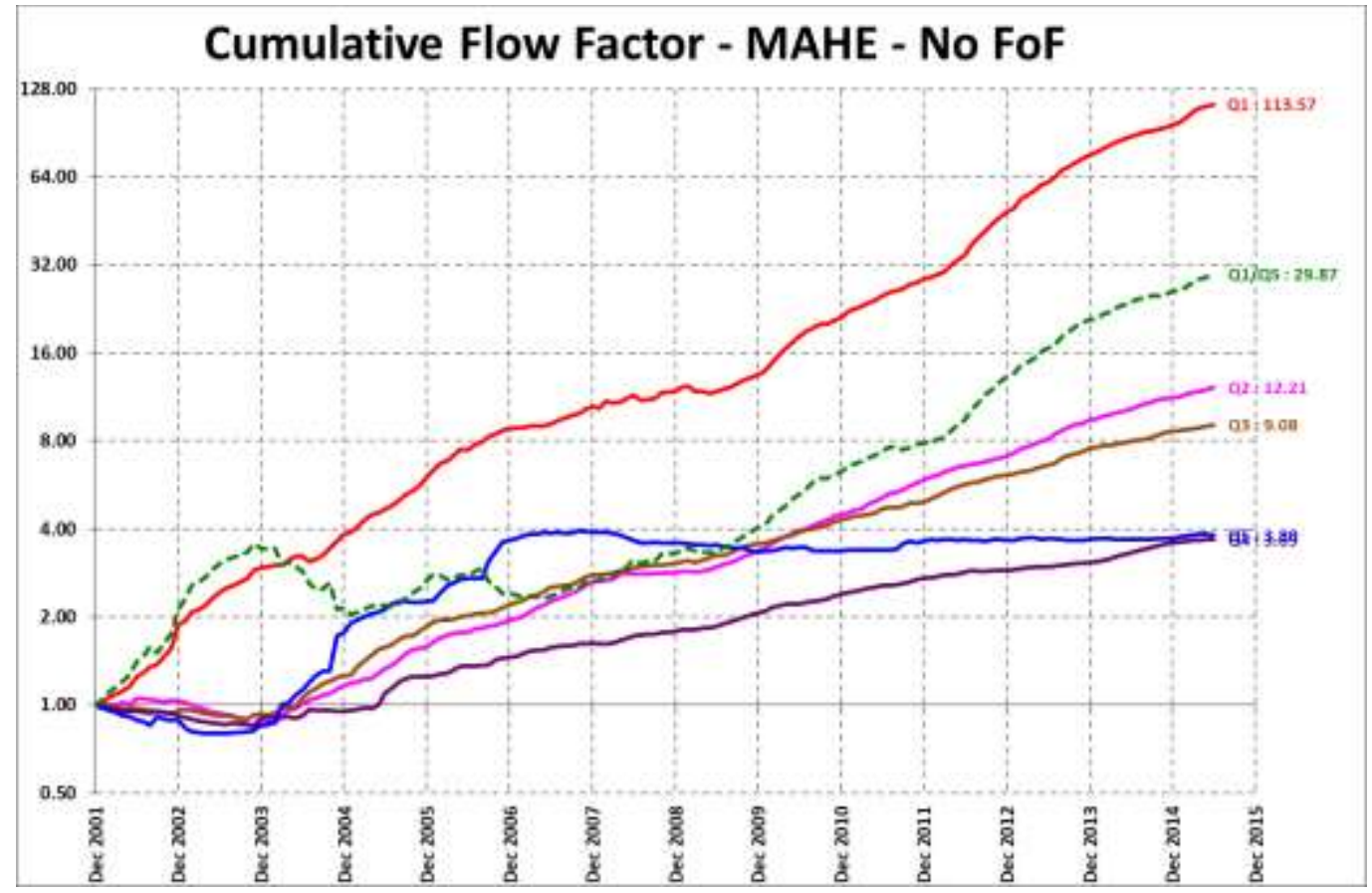

Figure 7: Cumulative annualised flows for quintiles - MultiAsset - High Equity

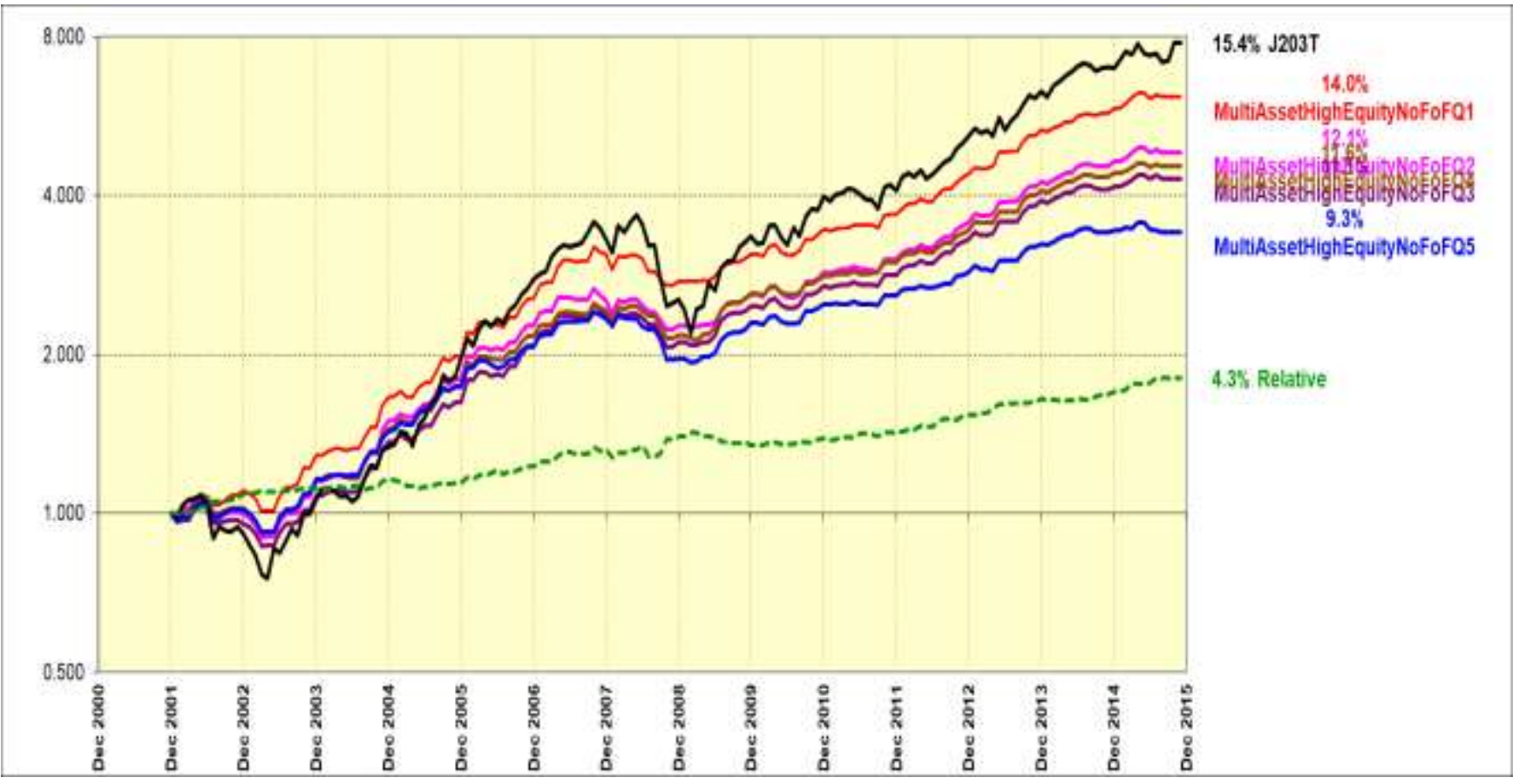

Figure 8: Cumulative annualised returns for quintiles - MultiAsset - High Equity 
Table 4: Cumulative annualised returns and flows for quintiles - MultiAsset - High Equity

\begin{tabular}{|l|c|c|c|c|c|c|c|}
\hline & Q1 & Q2 & Q3 & Q4 & Q5 & (Q1/Q5) & ALSI \\
\hline Annualised returns \% & $13.3 \%$ & $11.3 \%$ & $10.5 \%$ & $11.3 \%$ & $9.1 \%$ & $4.3 \%$ & $14.8 \%$ \\
\hline Annualised flow \% & $42.0 \%$ & $20.4 \%$ & $17.8 \%$ & $10.2 \%$ & $10.4 \%$ & $28.6 \%$ & \\
\hline $\begin{array}{l}\text { Cumulative Fund-flow } \\
\text { factor }\end{array}$ & 113.6 & 12.2 & 9.1 & 3.7 & 3.9 & 29.9 & \\
\hline
\end{tabular}

Friedmans's ANOVA test: $\mathrm{n}=162, \quad \mathrm{DOF}=4, \quad$ Significance $=5 \%$, Statistic $=167$

Result: Reject null hypothesis

Multi-asset High Equity (excl. FOF) - Top 10 MultiAsset - High Equity

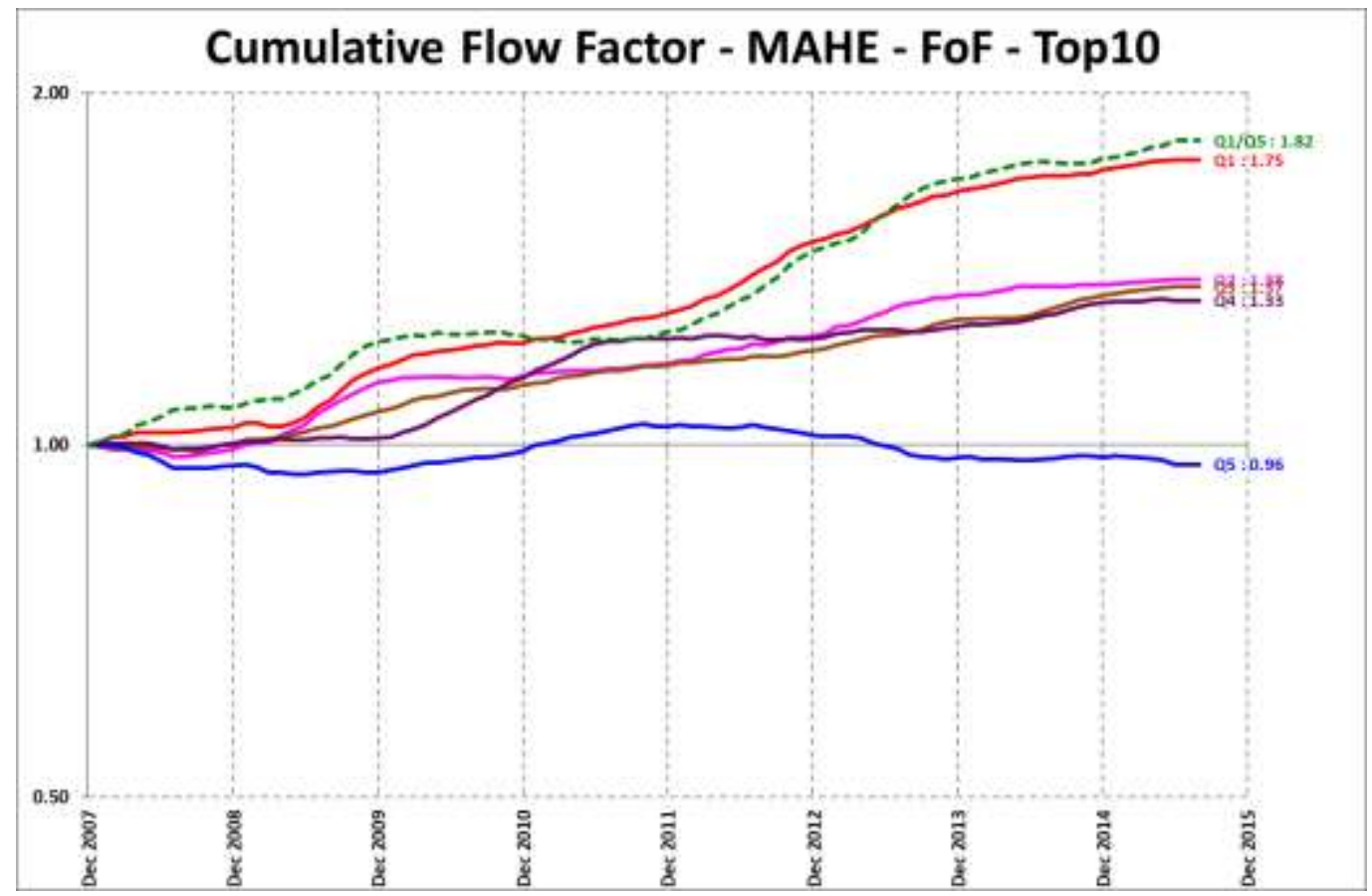

Figure 9: Cumulative annualised flows for quintiles - Top 10 MultiAsset - High Equity 


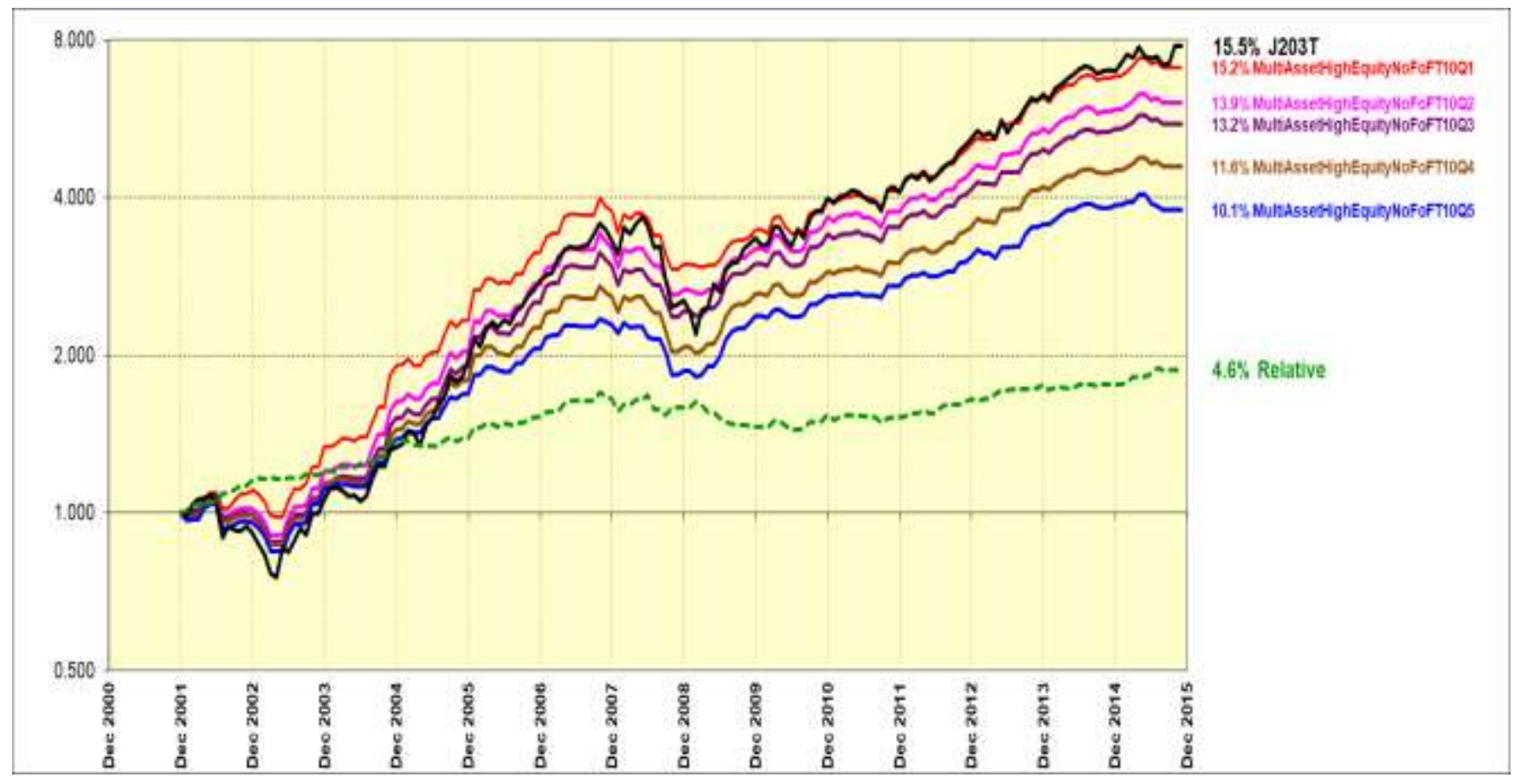

Figure 10: Cumulative annualised returns for quintiles - Top 10 MultiAsset - High Equity

Table 5: Cumulative annualised returns and flows for quintiles - Top 10 MultiAsset - High Equity

\begin{tabular}{|l|c|c|c|c|c|c|c|}
\hline & Q1 & Q2 & Q3 & Q4 & Q5 & (Q1/Q5) & ALSI \\
\hline Annualised returns \% & $14.9 \%$ & $13.7 \%$ & $12.9 \%$ & $11.4 \%$ & $9.9 \%$ & $4.9 \%$ & $14.8 \%$ \\
\hline Annualised flow \% & $7.6 \%$ & $4.3 \%$ & $4.1 \%$ & $3.8 \%$ & $-0.5 \%$ & $8.1 \%$ & \\
\hline $\begin{array}{l}\text { Cumulative Fund-flow } \\
\text { factor }\end{array}$ & 1.8 & 1.4 & 1.4 & 1.3 & 1.0 & 1.8 & \\
\hline
\end{tabular}

Friedmans's ANOVA test: $n=81, \quad D O F=4, \quad$ Significance $=5 \%$, Statistic $=92$

Result: Reject null hypothesis 


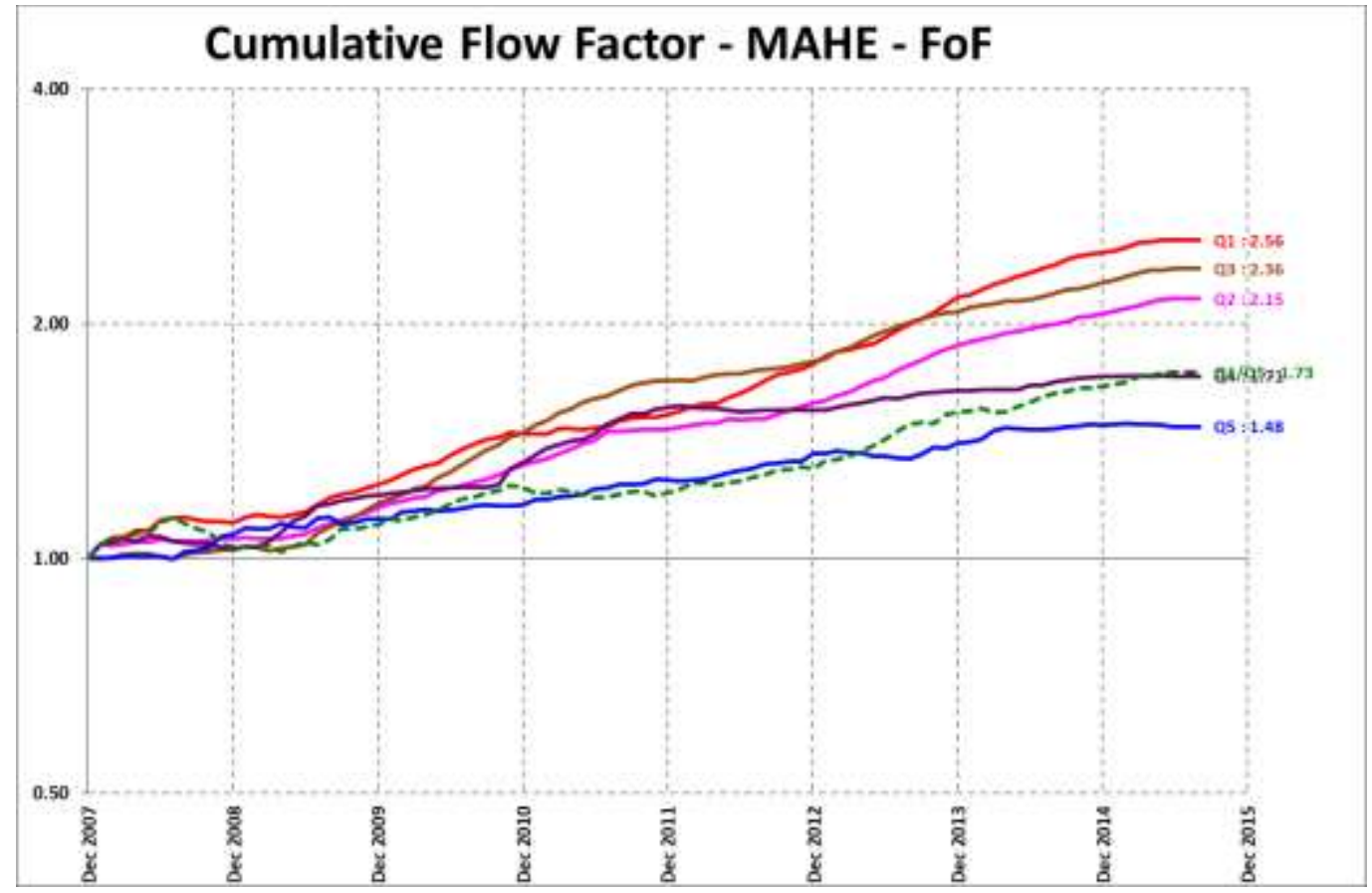

Figure 11: Cumulative annualised flows for quintiles - MultiAsset - FOFs

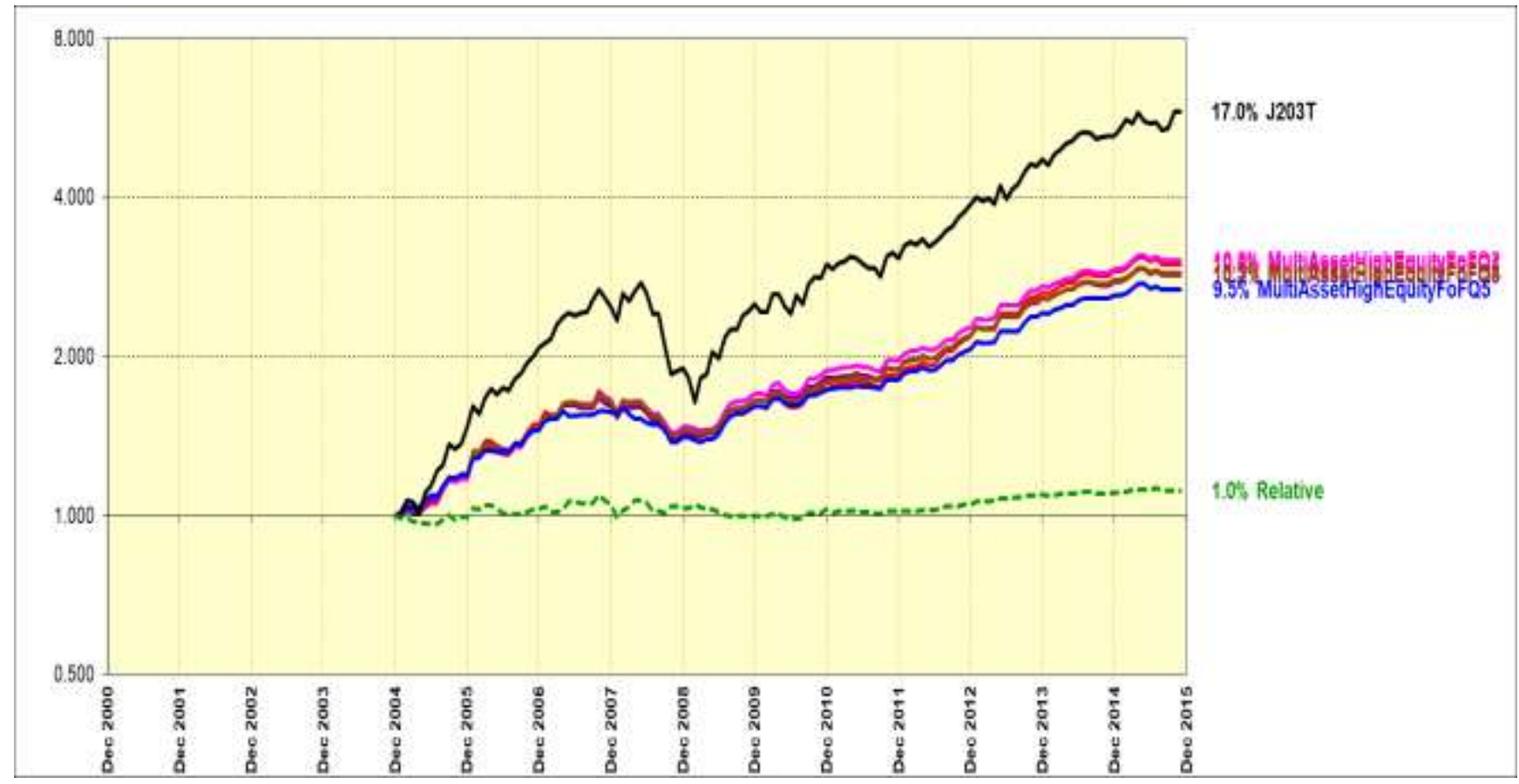

Figure 12: Cumulative annualised returns for quintiles - MultiAsset - FOFs 
Table 6: Cumulative annualised returns and flows for quintiles - MultiAsset - FOFs

\begin{tabular}{|l|c|c|c|c|c|c|c|}
\hline & Q1 & Q2 & Q3 & Q4 & Q5 & (Q1/Q5) & ALSI \\
\hline Annualised returns \% & $10.4 \%$ & $10.6 \%$ & $10.0 \%$ & $9.9 \%$ & $9.3 \%$ & $1.0 \%$ & $16.1 \%$ \\
\hline Annualised flow \% & $13.0 \%$ & $10.5 \%$ & $11.8 \%$ & $7.3 \%$ & $5.2 \%$ & $7.5 \%$ & \\
\hline $\begin{array}{l}\text { Cumulative Fund-flow } \\
\text { factor }\end{array}$ & $2.6 \%$ & $2.2 \%$ & $2.4 \%$ & $1.7 \%$ & $1.5 \%$ & $1.7 \%$ & \\
\hline \multicolumn{7}{|c|}{ Friedmans's ANOVA test: n=92, DOF=4, Significance=5\%, Statistic=53 } \\
Result: Reject null hypothesis \\
\hline
\end{tabular}

The final portion of our analysis is to measure the association between fund return and subsequent fund flows. To do this, we standardise the cumulative annualised fund returns (for each category) by calculating the excess return over/under the average return for the category. We plot these standardised returns against the annualised fund flows for each quintile, across all categories. Figure 13 below shows the result.

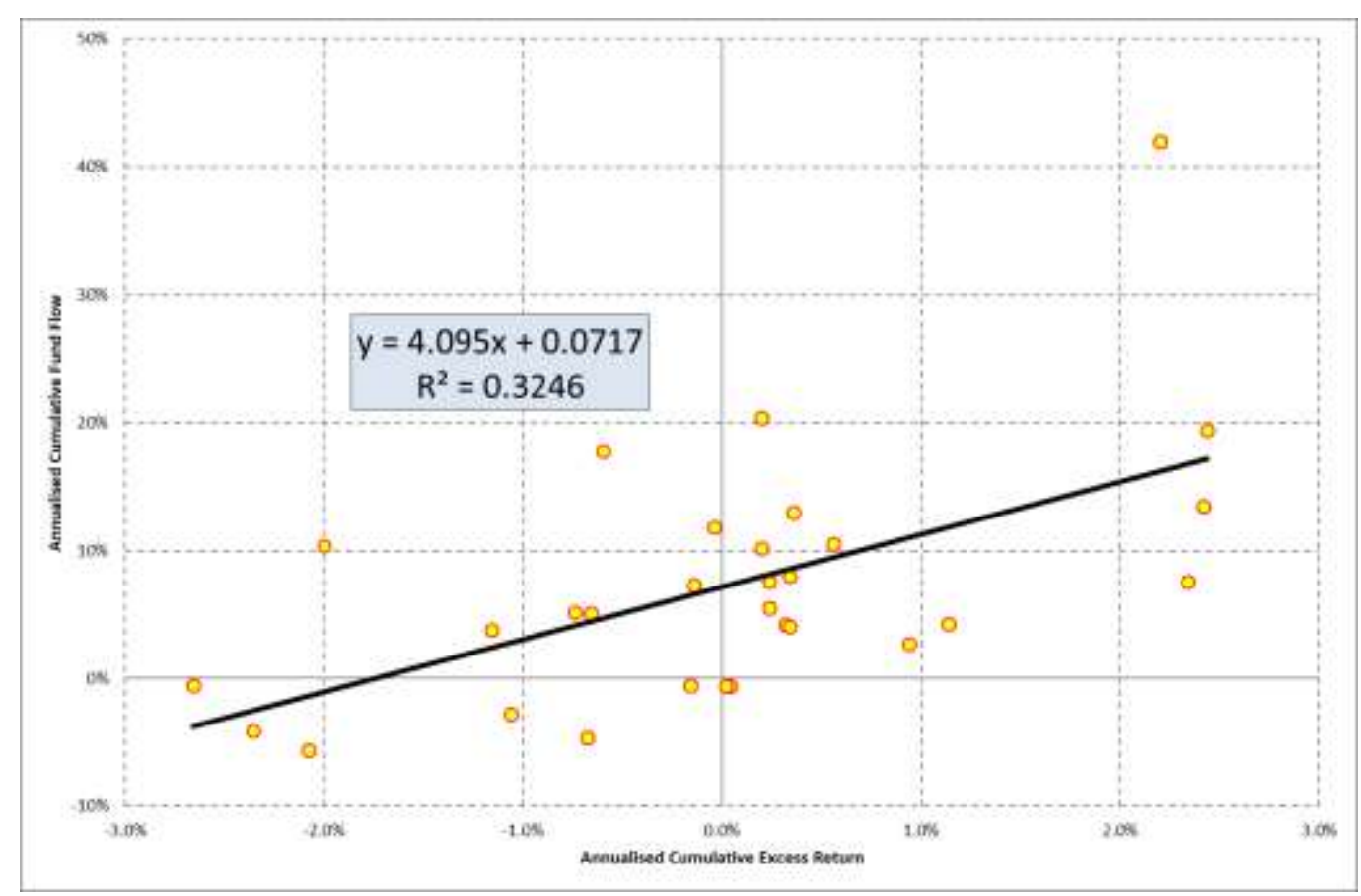

Figure 13: Scatterplot of annualised excess returns versus fund flows - all categories

\section{Discussion of results}

Figure 1 shows a large difference between the flows attracted by Quintile 1 (Q1) performers compared to all other quintiles for General Equity funds. From a relative perspective, Q1 attracted 19 times more flows than Q5. Other than Quintile 1 (and to a much lesser extent Q2), all the other quintiles gradually lose flows, and all quintiles except Q1 underperform the All Share Index (ALSI). In figure 2, Q1 shows an annualised return of $16 \%$ over the 15 year period, versus the total return of $14.8 \%$ of the All Share Index (J203T). The relative performance of Q1 versus Q5 is an annualised $4.4 \%$ pa. as shown by the (green) price relative line. 
Figure 3 shows the results for the Top 10 funds in the General Equity sector, excluding FOFs. The ten funds are ranked according to their performance and assigned into a quintile, depending on their relative performance to each other, with two funds per quintile. Again, the difference in subsequent flows between Q1 and Q5 is very significant, at more than 12 times. Only Q1 \& Q2 increase their fund sizes, and only Q1 outperforms the index. The relative performance of Q1 versus $\mathrm{Q} 5$ is $3.8 \% \mathrm{pa}$ (figure 4 ).

In figure 5 the FOF analysis only starts from 2004 due to the limited number of FOFs in existence prior to this. Although Q1 is (marginally) the best performing quintile, all the quintiles are bunched together and all significantly underperform the index, possibly on account of the higher fees charged. Q1 is the best performer, and (surprisingly) Q2 the worst performer. The difference in fund flows between $\mathrm{Q} 1$ and $\mathrm{Q} 5$ is only about two times. The relative performance of $\mathrm{Q} 1$ versus Q5 is only $0.4 \%$ pa (figure 6 ). It should be noted that the small sample size of FOFs in this category weakens this analysis.

Figure 7 shows the results for the Multi-asset High Equity funds. Again we observe a strong relationship between performance and subsequent flows, with a cumulative fund-flow factor of almost 30 times more going into Q1 versus Q5. All quintiles continue to attract flows and increase their fund sizes, but only from 2003 onwards. All the quintiles underperform the index. The relative performance of Q1 versus Q5 is 4.3\% pa (figure 8).

Figure 9 shows the top 10 funds in the Multi-asset High Equity category. The cumulative fund-flow multiple is only 1.8 times between Q1 and Q5, and the resulting fund returns are all ranked sequentially, and all underperform the index, except Q1 which more or less tracks the index. The relative performance of Q1 versus Q5 is $4.6 \%$ pa. which is the highest difference across all categories (figure 10).

Figure 11 shows the Multi-asset High Equity FOFs category. The fund returns are almost identical and the cumulative fund-flow multiple is only 1.7 times. All the funds underperform the index (figure 12).

In every instance, Friedman's ANOVA test statistic is significant at a $5 \%$ level, rejecting the null hypothesis and indicating that there is a significant difference between the fund flows between Q1 and Q5 (tables 1 - 6).

In figure 13 we show the association between fund returns and subsequent flows into funds. We show a significant coefficient of determination of $32 \%$ after fitting a straight line to the data. The equation of the line indicates that for every $1 \%$ of excess return (i.e. above the average return for the category of fund) approximately $4 \%$ p.a. more funds flow into the fund. Since we have averaged the data using quintiles, and we use the annualised cumulative returns and flow data 
over 15 years, the findings can be viewed as robust over the long term, given the statistical significance of the equation.

\section{Conclusions}

Our results support the theories predicting a positive association between fund performance and fund flows. As suggested by Ippolito (1992), we observe that good performance is an indicator to investors of quality and managerial ability (Huang et al., 2007) and that it is rewarded with significantly increased flows, and vice versa. For the 196 General Equity funds in our sample, we find that it is very much a case of "the winner takes it all". The top performing quintile of funds attracted 19 times more investment than the bottom quintile, at the expense of all the other quintiles, which (mostly) shrank. This finding is more significant than Blanchett's (2012) finding that top performing funds attracted the bulk of funds, at approximately three times the inflows of the bottom quartile.

We obtain similar results using the 165 funds in the Multi-asset High Equity category. Here we find that Q1 attracts almost 30 times the cumulative fund flow going into Q5, although none of the quintiles shrinks in size over the 15-year period.

Although our findings are less extreme when we examine the Top 10 funds in the General Equity and the Top 10 Funds in the Multi-asset High Equity categories, the conclusion is the same; quintile 1 dominates the fund flow at a Q1 to Q5 multiple of 12 times and two times respectively. Although we have fewer years of data for the FOFs categories, our findings are once again similar, but less extreme. Overall our results show strong support for performance being the main determinant of flows in an emerging market, as in developed markets (Chevalier \& Ellison, 1995; Goetzmann \& Peles, 1997; Goriaev, Nijman, \& Werker, 2008; Gruber, 1996; Ippolito, 1992; Sapp \& Tiwari, 2004; Sirri \& Tufano, 1998).

The fund flow differences between top and bottom quintiles we observed are however much greater than those reported by Ivković \& Weisbenner (2009). They report inflows of only $3.3 \%$ for funds in the top versus bottom quintile, which would translate into a flow multiple of around only two times over the 15-year cumulative period we measure.

We also show a significant association between excess return and fund flow (figure 13), our results supporting Rudman's (2008) hypothesis that investors tend to chase fund performance. We find that for every $1 \%$ p.a. return achieved above the benchmark, fund flow increases by approximately $4 \%$ p.a., and vice versa; somewhat stronger results than reported by Ben-Rephael et al. (2012).

Although we did not conduct a statistical test, we do not observe any obvious change in the trend across market cycles for fund flows around 2007, the start of the global financial crisis, which might indicate that the performance of funds is obviously different. Our findings in this instance do not 
support those of Karpaff (1987) who reported asymmetrical returns in the flow-performance link.

In conclusion, equity portfolios need to perform in the top quintile to attract significant flows. Should performance fall into lower quintiles, funds will at best, only double their fund size over a 15-year period and at worst, lose half their fund value over the same period. One important inference that can be drawn therefore, is that the South African unit trust industry is likely to experience significant consolidation. Of the 1225 funds in existence (many of which are small in value and not included in the study), only the top quintile in terms of performance attract flows. This has a fundamental impact on how portfolios are managed and how portfolio benchmarks are set. For instance, this study confirms that relative performance to peers is more important to investors than performance relative to the market or fund benchmark (Ivković \& Weisbenner, 2009).

A further implication for equity portfolio managers is that top-quintile performance needs to be achieved early in the fund's life, preferably within the first few years, since this is the most opportune time for better performance (as the fund is small), and for the fund to attract flows and generate profits for fund managers.

\section{References}

Alves, C., \& Mendes, V. (2011). Does performance explain mutual fund flows in small markets? The case of Portugal. Portuguese Economic Journal, 10(2), 129-147.

Association of Savings and Investments. (2015). ASISA Statistics Holdings 30 June 2015. ASISA. Retrieved from http://www.asisa.org.za/

Bailey, W., Kumar, A., \& Ng, D. (2011). Behavioral biases of mutual fund investors. Journal of Financial Economics, 102(1), 1-27.

Ben-Rephael, A., Kandel, S., \& Wohl, A. (2012). Measuring investor sentiment with mutual fund flows. Journal of Financial Economics, 104(2), 363-382.

Berk, J. B., \& Green, R. C. (2002). Mutual fund flows and performance in rational markets. National Bureau of Economic Research.

Blanchett, D. M. (2012). Fund Flows, Momentum, and Mutual Fund Performance. The Journal of Investing, 21(2), 83-91.

Cashman, G. D., Deli, D. N., Nardari, F., \& Villupuram, S. V. (2007). Investor behavior in the mutual fund industry: Evidence from gross flows. Available at SSRN 966360. 
Chevalier, J. A., \& Ellison, G. D. (1995). Risk taking by mutual funds as a response to incentives. National Bureau of Economic Research.

Edelen, R. M., \& Warner, J. B. (2001). Aggregate price effects of institutional trading: a study of mutual fund flow and market returns. Journal of Financial Economics, 59(2), 195-220.

Ferreira, M. A., Keswani, A., Miguel, A. F., \& Ramos, S. B. (2012). The flow-performance relationship around the world. Journal of Banking \& Finance, 36(6), 1759-1780.

Ferruz, L., Ortiz, C., \& Sarto, J. L. (2009). Decisions of domestic equity fund investors: determinants and search costs. Applied Financial Economics, 19(16), 1295-1304.

Field, A. (2013). Discovering statistics using IBM SPSS statistics. Sage.

Goetzmann, W. N., \& Peles, N. (1997). Cognitive dissonance and mutual fund investors. Journal of Financial Research, 20(2), 145-158.

Goriaev, A., Nijman, T. E., \& Werker, B. J. (2008). Performance information dissemination in the mutual fund industry. Journal of Financial Markets, 11(2), 144-159.

Griffin, J. M., Nardari, F., \& Stulz, R. M. (2007). Do investors trade more when stocks have performed well? Evidence from 46 countries. Review of Financial Studies, 20(3), 905- 951.

Gruber, M. J. (1996). Another puzzle: The growth in actively managed mutual funds. The Journal of Finance, 51(3), 783-810.

Huang, J., Wei, K. D., \& Yan, H. (2007). Participation costs and the sensitivity of fund flows to past performance. The Journal of Finance, 62(3), 1273-1311.

Ippolito, R. A. (1992). Consumer reaction to measures of poor quality: Evidence from the mutual fund industry. Journal of Law and Economics, 45-70.

Ivković, Z., \& Weisbenner, S. (2009). Individual investor mutual fund flows. Journal of Financial Economics, 92(2), 223-237.

Karpoff, J. M. (1987). The relation between price changes and trading volume: A survey. Journal of Financial and Quantitative Analysis, 22(01), 109-126.

Li, D., \& Zhang, L. (2010). Does q-theory with investment frictions explain anomalies in the crosssection of returns? Journal of Financial Economics, 98, 297-314. 
Muller, C., \& Ward, M. (2013). Style-based effects on the Johannesburg Stock Exchange: A graphical time-series approach. Investment Analyst Journal, 77.

Pillay, N., Muller, C., \& Ward, M. (2010). Fund size and returns on the JSE. Investment Analysts Journal, 39(71), 1-11.

Rudman, R. J. (2008). An empirical study of the determinants of net investment flows of South African General Equity unit trusts. Meditari Accountancy Research, 16(1), 95-116.

Sapp, T., \& Tiwari, A. (2004). Does stock return momentum explain the "smart money" effect? The Journal of Finance, 59(6), 2605-2622.

Saunders, M., \& Lewis, P. (2012). Doing Research in Business and Management. Edinburgh Gate: Pearson.

Sawicki, J. (2001). Investors' differential response to managed fund performance. Journal of Financial Research, 24(3), 367-384.

Shleifer, A., \& Vishny, R. (1997). The limits of arbitrage. Journal of Finance, 52(1), 35-55.

Singal, V., \& Xu, Z. (2011). Selling winners, holding losers: Effect on fund flows and survival of disposition-prone mutual funds. Journal of Banking \& Finance, 35(10), 2704-2718.

Sirri, E. R., \& Tufano, P. (1998). Costly search and mutual fund flows. The Journal of Finance, 53(5), 1589-1622.

Ying, C. C. (1966). Stock market prices and volumes of sales. Econometrica: Journal of the Econometric Society, 676-685. 